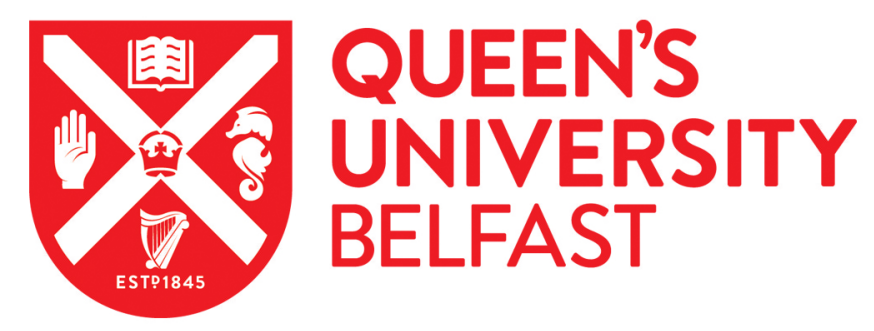

\title{
Wearable antennas for medical monitoring systems
}

Conway, G. A., \& Scanlon, W. G. (2015). Wearable antennas for medical monitoring systems. In Proceedings of 2015 International Workshop on Antenna Technology (iWAT) (pp. 19-21). Institute of Electrical and Electronics Engineers Inc.. https://doi.org/10.1109/IWAT.2015.7365348

\section{Published in:}

Proceedings of 2015 International Workshop on Antenna Technology (iWAT)

\section{Document Version:}

Peer reviewed version

\section{Queen's University Belfast - Research Portal:}

Link to publication record in Queen's University Belfast Research Portal

\section{Publisher rights}

(c) 2015 IEEE. Personal use of this material is permitted. Permission from IEEE must be obtained for all other uses, in any current or future media, including reprinting/republishing this material for advertising or promotional purposes, creating new collective works, for resale or redistribution to servers or lists, or reuse of any copyrighted component of this work in other works

\section{General rights}

Copyright for the publications made accessible via the Queen's University Belfast Research Portal is retained by the author(s) and / or other copyright owners and it is a condition of accessing these publications that users recognise and abide by the legal requirements associated with these rights.

Take down policy

The Research Portal is Queen's institutional repository that provides access to Queen's research output. Every effort has been made to ensure that content in the Research Portal does not infringe any person's rights, or applicable UK laws. If you discover content in the Research Portal that you believe breaches copyright or violates any law, please contact openaccess@qub.ac.uk. 


\title{
Wearable Antennas for Medical Monitoring Systems
}

\author{
Gareth A. Conway \& William G. Scanlon \\ Wireless Communication Systems (WCS), Institute of Electronics, Communications and Information Technology \\ Queen's University of Belfast, Belfast, UK \\ g.conway@qub.ac.uk,w.scanlon@qub.ac.uk
}

\begin{abstract}
A wearable silver nano particle inkjet printed antenna suitable for wireless biomedical sensing is presented. The performance is evaluated on a synthetic variable layered phantom test-bed, representative of human tissue for operation in the 868/915 MHz, and $2400 \mathrm{MHz}$ industrial, scientific and medical frequency bands. Antenna radiation efficiency measurements on the phantom were compared with antennas prototyped with copper. Total radiation efficiencies up to $-6.5 \mathrm{~dB}$ are reported, with less than $0.5 \mathrm{~dB}$ difference in performance between copper and silver nano particle variants, showing promising application for low-cost disposable wireless sensing.
\end{abstract}

Keywords-Wearable Antennas; Wireless Medical Sensors; Bodycentric Communications, Human tissue phantoms, Conductive inkjet printing; Wireless Sensing; Disposable Radio.

\section{INTRODUCTION}

There has been an unprecedented increase in momentum of antennas and propagation research to address challenges in wireless biosensor networks. These biological sensors are generally placed on or in very close proximity to the testsubject to be measured. A common trend in antenna design, is to make the antenna physically smaller and more compact [1], meaning that it is more comfortable and less obtrusive to the user. However, size is not the only factor which must be carefully considered for clinical medical applications. This paper examines the characteristics of wearable antennas at ISM frequency bands of $868-915 \mathrm{MHz}$ and investigates their suitability for wireless medical vital sign monitors.

Wireless Vital Signs Monitors (VSM), typically measure temperature, heart rate, respiration and more recently blood oxygen saturation levels. To do this, the sensor device broadly incorporates low-power digital processing technology, RF circuitry and an integrated antenna. The wireless performance of the device is largely influenced by the antenna performance and in some cases, the propagation environment. Antenna performance issues can be further compounded when there is a direct conductive connection to the human body tissue, which is often the case with chest worn VSMs [2].

A key factor which is often overlooked in antenna performance evaluation is system performance on a range of human tissue morphologies, which can often greatly influence antenna selection [3]. This is of particular importance in biomedical sensing applications, where reliability is often critical. Human body effects can be mitigated by selecting antenna designs with relatively large groundplanes, to reduce antenna-tissue coupling [4]. Although, these antenna types tend to perform favorably on the human body, they take up a much larger volume and can in some cases, be more obtrusive to the user, particularly if worn for an extended time period. Nonetheless, it is important to characterize the wearable antenna and system on a range of body types or multiple phantom structures, typical of its operating environment characteristics.

\section{MeASuREMENT Methodology}

\section{A. Human Tissue Testbed}

To overcome inevitable variations in human test subjects and to comparatively analyze the performance of different VSM systems, a repeatable measurement phantom is required. Such experimental measurement verification platforms, representative of the broad range of human bodies in the population are considerably lagging behind numerical and digital phantoms [1].

An ideal phantom would have variable tissue thicknesses, where, the wearable antenna performance bounds could be established to verify that a device operating on any human test subject would fall within the performance bounds, as measured on the test-bed. In this study a tissue phantom testbed was used that is electromagnetically representative of the spread in tissue properties of the thorax region of a wider range of the human population (Fig. 1) [2]. Furthermore, to fully characterize the performance of these antennas, all components must be present, particularly large electrically conductive objects, and more critically, any conductive connection to the body, which may influence the radiation characteristics of the device.

Previous work [2], compared antenna radiation efficiency measurements on the phantom to measurements on the thorax region of a human test subject as part of a validation study. The results showed that the phantom was representative of the human body for the application of wireless vital sign monitors, where conductive connections are made to the tissue.

\section{WEARbLE ANTENNA SELECTION}

Wearable antennas suitable for chest worn VSMs must be low profile and physically compact and ideally they would conform to the surface of the body. Furthermore, for the USA Food Drugs Agency (FDA) and other regulatory approvals, there are advantages in biomedical sensors being disposable [5] to avoid risk of cross-contamination and patient infections. Therefore, conductive inkjet printing on low cost polymers is an attractive solution. This manufacturing process could mean 
that the antennas and sensors could be easily mass-produced, lowering production cost. However, this approach presents additional challenges to the antenna designer as they cannot incorporate expensive dielectric substrates. There has been little published about the relative performance of conductive inkjet printed wearable antenna performance at microwave frequencies. In this work we investigate the performance of a nano silver inkjet printed antenna (Fig. 2) in comparison to the same antenna geometry prototyped with copper. Although printed dipole antennas placed in parallel to the skin surface, exhibit strong coupling to the tissue, a flared dipole antenna was selected for experimental measurement for the following reasons: (a) the antenna can be printed on flexible substrate which will conform to the surface of the human body; (b) the impedance bandwidth of the antenna is relatively large, which will mitigate against resonant frequency shifts and detuning when mounted on variable tissue morphologies; (c) the antenna size can be readily optimized if the ink prototype performance is acceptable.

The antenna was printed using a standard Epson workforce 30 inkjet printer with Metalon ink. The surface profile, obtained using a Talysurf CCI 6000 Optical 3D Profiler (white light interferometer) is shown in Fig. 3. The inkjet produces a relatively uneven ink deposit for a single layer, and it is expected that performance could be improved with higher quality printing technology of possibly addition layer deposits. The antenna was optimized to ensure small deviations in resonant frequency did not result in the antenna having poor radiation efficiency characteristics due to impedance mismatch losses. A test PCB with balun was used to test the individual antennas and U.fl coaxial connectors were used to connect the antenna to a Rhode and Schwarz ZBN vector network analyzer.

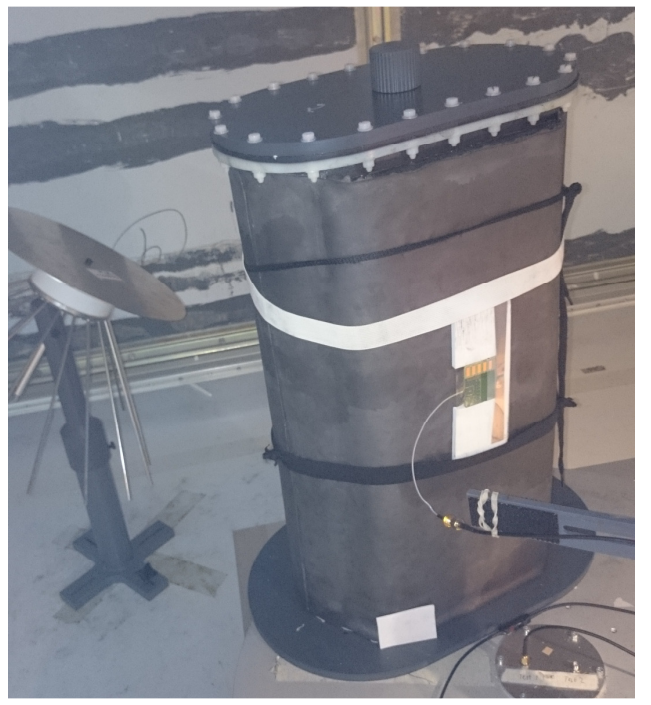

Fig. 1. Human tissue phantom test-bed measurement in a Bluetest reverberation chamber.
Fig. 2. Nano Silver InkJet Printed Antenna for $860-930 \mathrm{MHz}$

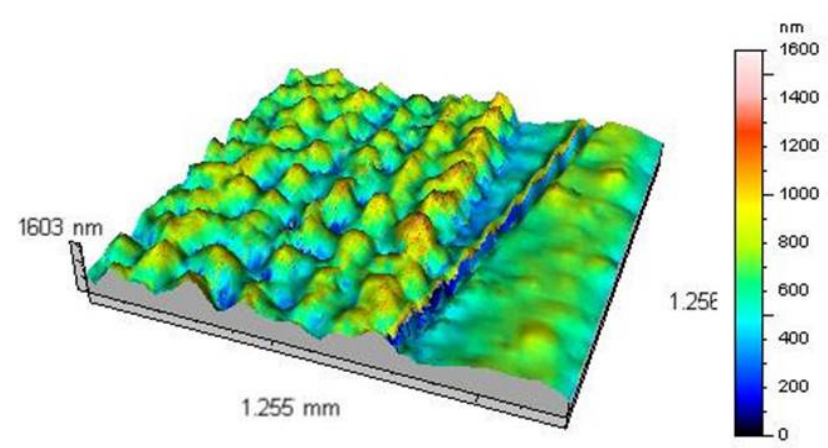

Fig. 3. Printed antenna surface profile

\section{A. Experimental Measurements}

The return loss $\left(\left|S_{11}\right|\right)$ and the radiation efficiency of the antennas were measured on the physical tissue phantom. All measurements were performed in a $2.5 \mathrm{~m}$ by $2.5 \mathrm{~m}$ by $2.5 \mathrm{~m}$ reverberation chamber installed by Bluetest.se.. The antennas were mounted on $5 \mathrm{~mm}$ Rohacell HF51 foam $\left(\varepsilon_{\mathrm{r}}=1.07\right)$, for consistent tissue separation distance. The return loss plots for the antennas are shown in (Fig. 4).

The total radiation efficiency of the antennas were measured on each side of the tissue phantom, composed of a lean side (LS) with thin SAT tissue layer, and a thick side (TS) with relatively larger SAT tissue layer. The printed ink and copper antenna performance results are compared in (Fig. 5). The average efficiencies over each ISM band have been extracted and are detailed in Table 1.

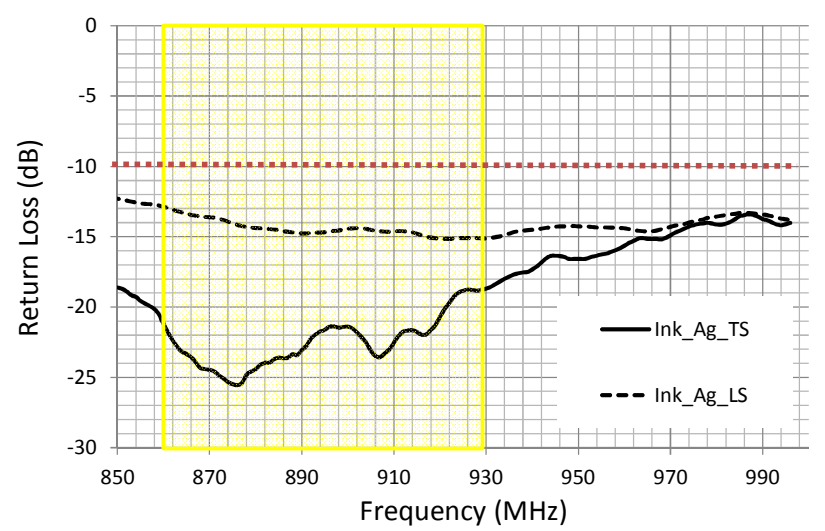

Fig. 4. Measured return loss plots for the phantom mounted antennas with highlighted ISM frequency bands of interest

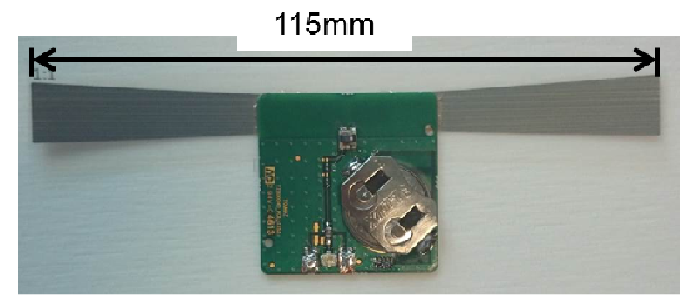




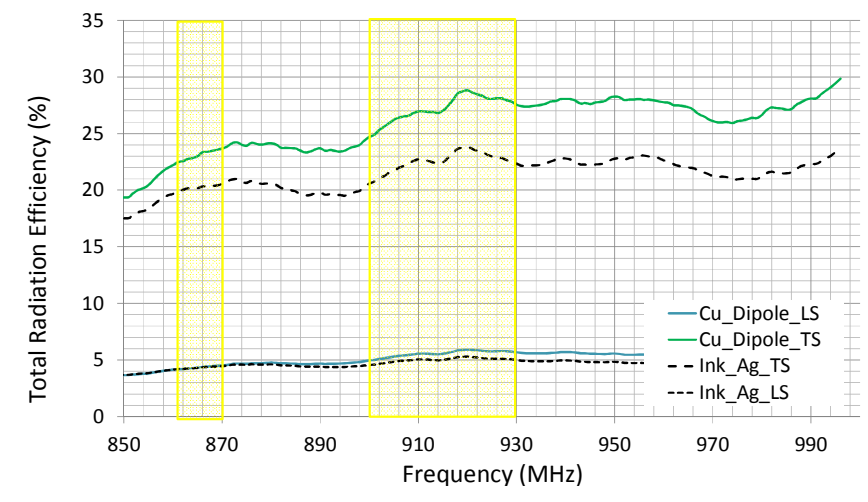

Fig. 5. Measured total radiation efficiency results for phantom mounted antenna with highlighted ISM frequency bands of interest.

\section{RESULTS DISCUSSION}

The total radiation efficiency (i.e., inclusive of mismatch losses) of the conductive ink dipole antennas were measured on the physical tissue phantom and compared to the same antennas comprised of copper, spaced $5 \mathrm{~mm}$ from the phantom using Rohacell foam (Figure 2). The measured radiation efficiency is between $5-27 \%(-13.0$ to $-5.7 \mathrm{~dB})$. Maximum total radiation efficiency was achieved on the phantom side with the thickest SAT tissue layer. Minimum performance was achieved where the SAT tissue layer was thinnest, which meant that the antenna was position closer to the inner phantom tissue layer, which had a relatively larger electrical conductivity. The difference in wearable radiation performance of the antennas prototyped using conductive ink in comparison to copper is less than $0.5 \mathrm{~dB}$. This was primarily due to the conductivity of the nano silver ink. This could be improved by depositing more than one layer of ink. However, multiple layer printing is challenging using inkjet printer technology used here, as it uses an optical feeding system for the substrate. These results show that conductive ink can be used for antennas at the $868 / 915 \mathrm{MHz}$ band using simple ink-jet manufacturing processes.
TABLE I. COPPER VS NANO SILVER INK ANTENNA PERFormancE

\begin{tabular}{|l|c|c|}
\hline \multirow{2}{*}{ Antenna } & \multicolumn{2}{|c|}{ Radiation Efficiency } \\
\cline { 2 - 3 } & $\begin{array}{c}\text { Average Total Rad Eff } \\
(\%)\end{array}$ & $\begin{array}{c}\text { Average Total Rad Eff } \\
(\boldsymbol{d B})\end{array}$ \\
\hline Cu_Dipole_TS & 27.2 & -5.7 \\
\hline Cu_Dipole_LS & 5.6 & -12.6 \\
\hline Ink_Ag_TS & 22.7 & -6.4 \\
\hline Ink_AG_LS & 5.0 & -13.0 \\
\hline \multicolumn{2}{r}{} & \multicolumn{2}{c|}{${ }^{\text {a. }}$ LS=LeanSide less SAT Tissue } \\
\end{tabular}

\section{CONCLUSIONS}

This measurement analysis shows that conductive printed ink technology is an attractive candidate for low-cost biomedical wireless sensing technology. The phantom test-bed proposed is a promising platform for the comparative analysis and measurement of wireless VSM systems. Future work will optimize the test-bed to be representative of the broad range of human thorax tissue compositions of the human population, which impact the antennas and propagation performance of wearable wireless sensor systems.

\section{References}

[1] P.S. Hall and Y. Hao, Antennas and Propagation for Body-Centric Wireless Communications, Artech House Publisher, 2012.

[2] G. A. Conway, W. G. Scanlon, C. Nunn, A. Burdett, 'Layered RF Phantom Characterisation for Wireless Medical Vital Sign Monitors,' IEEE International Symposium on Antennas and Propagation. 2013.

[3] G. A. Conway, W. G. Scanlon \& S. L. Cotton, "The Performance of OnBody Wearable Antennas in a Repeatable Multipath Environment," IEEE Antenna \& Propagation Symposium, San Diego, UK, Jan 2008.

[4] G.A. Conway \& W. G. Scanlon, "Antennas for Over-Body-Surface Communication at $2.45 \mathrm{GHz}$," IEEE Trans. Antennas and Prop., 2008.

[5] K. Meehan Arias, 'Contamination and Cross Contamination on Hospital Surfaces and Medical Equipment,' Web Source: www.initiativespatientsafety.org, March 2012. 